\title{
The consequences of the use of online sources of information and mobile devices in university classes
}

\author{
Przemysław Polak, Warsaw School of Economics, ppolak@sgh.waw.pl
}

\begin{abstract}
This article presents the observation results of the use of different media by students during university computer lab courses. The observation results were supplemented with survey results on general preferences of the students regarding the forms of access to information. This study showed that students prefer to use electronic resources over traditional printed ones, as well as their clear commitment to the use of mobile devices. The students also preferred graphic forms of presentation over in-depth textual analyzes. The observation proved that many students have a problem with assessing the quality of information available on the Internet. Thus, it is proposed to use terms with alternative knowledge or post-truth knowledge to emphasize the importance of the problem of information source credibility.
\end{abstract}

Keywords: Information quality, alternative knowledge, pop knowledge, learning, Internet, information sources, and mobile devices.

\section{Introduction}

Progress in the field of information technology and the widespread availability of electronic devices as well as telecommunication links have affected many areas of life, including higher education. Large number of publications has been devoted both to technological solutions and the possibilities of their application, as well as changes in teaching methods, didactics organization, or the evolution of the role of universities in the modern world (Laurillard, 2013; Venkatesh, Rabah, Fusaro, Couture, Varela, \& Alexander, 2016). Contrary to pseudo-prophetic voices, e-learning has not changed significantly the face of higher education institutions, as it has not changed lower-level education (Downes, 2005; Selwyn, 2007). On the other hand, it had a greater impact on the area of specialist training, lifelong learning, and the sphere of selfeducation (Gaebel, Kupriyanova, Morais, \& Colucci, 2014).

Naturally, the use of information technology brings many benefits in traditional education, such as easier access to information resources, also on a global scale, interactive and multimedia information resources, the possibility of long-distance communication, etc. (Dahlstrom \& Jacqueline, 2014). However, the main and the most effective form of teaching at the university level is face-to-face interaction between a teacher and a student. Virtual interaction cannot compete with the richness of a face-to-face meeting. Therefore, seminars, tutorials, and laboratory classes remain the basic, while at the same time, most highly effective form of teaching methods. On the other hand, e-learning is effectively replacing simple, one-direction learning methods in terms of knowledge transfer: working with textbooks and listening to 
traditional lectures, thus, making teaching more efficient and effective (Zhuang, Ma, Xie, Leung, Hancke, \& Wang, 2016). In addition, e-learning eliminates time and distance limits enabling remote multi-channel communication (Clark \& Mayer, 2016). Nevertheless, traditional forms of lectures, seminars, and tutorials also benefit from information technology due to the use of special solutions dedicated to an educational process, such as overhead projectors and multimedia boards, or computer labs, as well as devices used individually by students: portable computers, tablets, and smartphones. At the same time, students extensively utilize websites and social networking services, particularly Wikipedia, to obtain information for personal, as well as study related purposes (Garrison, 2015; Guy, 2012; Kim, Sin, \& Tsai, 2014; Shen, Cheung, \& Lee, 2013). Smartphones have become a student's basic equipment, as was once a paper notebook, a pencil, a photocopy, and a textbook. Students use their smartphones to access teaching materials or supporting information, which are normally accessible through the Internet (Anshari, Almunawar, Shahrill, Wicaksono, \& Huda, 2017). However, students prefer less rich e-learning content when using mobile devices (Kon, Kobayashi, Sakurai, Watanabe, Yamaga, \& Ono, 2017).

In addition to the obvious benefits of using modern technologies, there are also negative effects. The possibility of recording the content of the lecture and later listening to it by students as well as providing official lecture recordings in higher education raised some controversy (McGarr, 2009; O’Callaghan, Neumann, Jones, \& Creed, 2017). Students rely more on search engines for fulfilling their information needs instead of library resources (Ko, Chiu, Lo, \& Ho, 2015).

The use of mobile devices with access to the Internet during learning is associated with the phenomenon of multitasking. Many studies confirmed that the significant time spent working with these devices was devoted to other non-learning activities (Rosen, Carrier, \& Cheever, 2013; Tassone, Liu, Reed, \& Vickers, 2017; Terry, Mishra, \& Roseth, 2016; Tindell \& Bohlander, 2012). Various studies showed that multitasking had a negative impact on student performance (Calderwood, Ackerman, \& Conklin, 2013; Lepp, Barkley, \& Karpinski, 2015; Patterson, 2017).

Any one with many years of experience in conducting academic classes should consider raising doubts whether the use of those devices by students in individual work during classes has a positive impact on the course of classes and whether it improves the quality of the teaching process. The disappearance of elementary skills among students, such as taking notes, leading to difficulties in the reproduction of reasoning and the interpretation of material presented in previous classes is significantly noticed nowadays. The deep reflections and own opinions were replaced with the results of Internet search engines and contents from social media resources, in the same way as in many areas, expert knowledge was replaced by pop knowledge (Birchall, 2011).

To our observations, however, stand in opposition to the general admiration of technology, new media and the alleged proficiency of young people in the digital world. Hence, the idea of verifying such observation in a controlled experimental environment was emerged. Thus, the aim of this research was to study how students used new information technologies during classes and whether the use of electronic devices had an impact on general student work methods. That could 
have led to the identification of potential problems resulting from the intensive use of electronic devices and digital information sources in university classes.

\section{Research Method}

The research plan included conducting two stages of the study: a direct observation of students' behavior in class and a survey of students. In order to ensure the reliability of study results, the observation was carried out during regular university classes. The students were not aware of their participation in the study (allowed under the research protocol rule in Poland). The observer was introduced to the classes under the pretext of the presence of a trainee who was assigned to conduct those classes in the future as a substitute for an experienced lecturer. In fact, he did not take notes about the course content and teaching methods, but he observed and recorded students' behavior during classes. The observer used a sheet containing a map of seats in the computer laboratory and marked on it identified behaviors of individual students. During the class, he was sitting at the back of the room from where he had a good visibility of computer screens, or he was walking around the room pretending that he was accompanying the teacher who was giving instructions to individual students.

The study was conducted during the computer lab classes in Introduction to Business Information Systems. It is a compulsory course in the first year of undergraduate studies for all students of the Warsaw School of Economics (SGH, 2016). The observation was conducted during the classes taught in English addressed to both foreign students and Poles, generally studying both in English and in Polish. This is due to the principle that students of Polishlanguage studies have the opportunity to choose individual courses also in foreign languages.

The study was conducted on three student groups, altogether 48 students were present on that day. Based on the review of names and surnames, it can be assumed that there were 19 Poles and 29 foreigners in the surveyed group. The largest group of foreigners came from the countries of the former Soviet Union, primarily from Ukraine, but also from central Asia, i.e. Kazakhstan and Uzbekistan. In addition, there were representatives of various European and Asian countries in the group. Due to the need to maintain the anonymity of the respondents, no precise data about the students' country of origin were documented. The group included 22 females and 26 males.

During the observed classes, students were given the task to perform individually an exercise in modeling the functions of an information system using Data Flow Diagrams (DFD). They received a case study containing a verbal description of the operation of a dental clinic and on that basis, they were to develop a functional model of the information system. The description had been simplified so that it was perfectly understandable for first-year students and the model was feasible to draw during a two-hour class. During previous classes, students had been introduced in the form of a lecture with the basic principles of modeling using DFDs. Basic exercises had been also carried out to verify the correct application of modeling rules, regarding such elements as occurrence of the so-called "black holes" or the consistency of diagrams as part of process decomposition. The students had been also familiarized with Microsoft Visio, which was used as modeling tool during classes. Deliberately, however, the analysis of an example of building a complete model had not been carried out in advance with the students. As a result, the 
students had to show some self-reliance in applying the previously learned rules, and they could not mindlessly copy a solution from another well-known example.

In addition to relying on the knowledge acquired during the previous classes, students had at their disposal a textbook specially designed for the course (Polak, 2015). They also had access to the electronic version of the textbook (Youdron, 2006) available online in the public domain, with the indication of the chapters containing useful content for them. Students also had access to an electronic handout containing slides describing in detail the material presented during earlier lectures on DFD modeling. Independently having access to the Internet all the time during the observed classes, students could use any of the resources available online.

Just after the class, the students were asked to fill in the survey instrument about their preferences concerning methods of information retrieval. None of the participants refused to do it. The results of the survey were used as the source of information for the analysis of student preferences in accessing information. Three aspects were measured in the survey: accessing encyclopedic information, the popularity of information sources on current events, and reading habits. The survey was a part of a broader long-term research project on the use of new information media by students in accessing a variety of information resources and in interpersonal communication (Polak, 2011, 2013, 2016). Some of the content publicly available online in the Internet that could have been used by students during the observed classes to assess the quality of that content were also reviewed.

\section{Observation Results}

During the lecture preceding the actual part of the observation, it was noticed that most of the students did not take notes at all during the lecture or did so in a very rudimentary form. In addition, several students took pictures of drawings made on the board. One student took pictures during the class, due to sitting in the first row seat. The remaining students took pictures of drawings after the end of the lecture. Especially in the latter case, the usefulness of such material is questionable, because the drawings were repeatedly redrawn by the lecturer in order to present alternative versions of diagrams, as well as to discuss incorrect solutions. As a result, drawings left on the board after the classes may have included inconsistencies, and without proper commentary or deeper understanding of the topic discussed could have led to errors.

The observation that many students did not take any notes throughout the lecture was confirmed during the observed classes. It turned out that only 15 students (31.3\% of the surveyed group) used previously made notes on single sheets or in notebooks (See Figure 1). On the other hand, all students used, to a greater or lesser extent, an extensive set of slides, also containing examples of diagrams or their fragments. There were 22 students that opened slides on lab computer screens, 25 students used their own smartphones to open the slides, and one a tablet was observed used for that purpose. The second approach had an undoubted advantage that students did not have to constantly switch between slides and the Microsoft Visio window. Due to the relatively small size of the screens of lab computers, the possibility of simultaneous view of reasonable size windows was virtually impossible, it required constant switching of an application window visible on top. On the other hand, it appears that on the average size of a smartphone, some elements of the graphics on the slides were illegible and their viewing 
required burdensome zooming in and out of the image. Moreover, it was a significant fact that none of the students had slides in printed form, even though they were available as a PDF file long before these class sessions. Consequently, none of the participants used the technique of taking notes on printed slides.

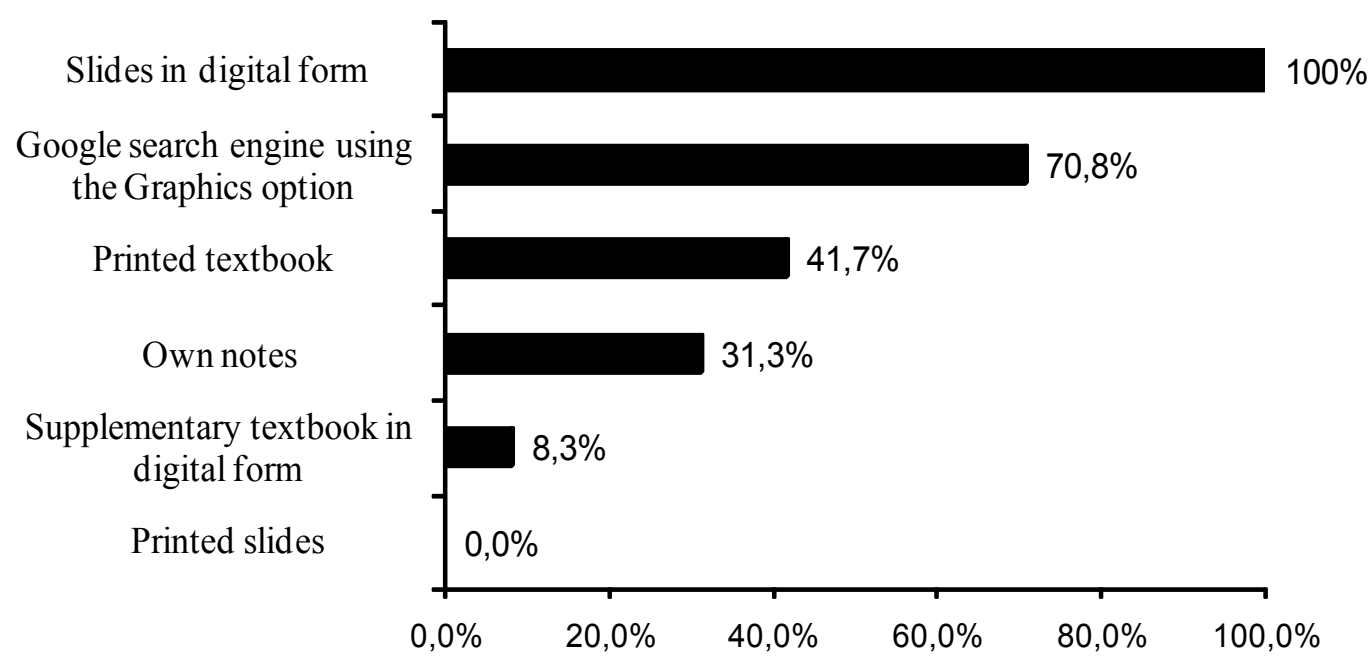

Figure 1. The Percentage of Students Using Specific Resources During Observed Classes

During the exercise, only 20 students $(41.7 \%$ of the group) used the basic textbook (Polak, 2015). This is particularly surprising, because the textbook is available in a large number of copies to be borrowed at the university library and on the day of the observation several copies were still available for borrowing. Moreover, four students did not use the original textbook, but its photocopy. What's more, the observer noticed handwritten notes only on one of those photocopies. None of the students was using a scanned copy of the textbook. However, it should be noted that the textbook is not legally distributed in the form of an e-book. In addition, the observer spotted three people viewing the electronic version in PDF format of the supplementary textbook by Yourdon (2006) on a computer screen.

A very interesting phenomenon that was observed was the use of Internet resources. At least 34 participants of the classes (70.8\% of the group) used the Google search engine using the Graphics option. The most frequently searched phrase was: 'dfd' or 'data flow diagram'. Afterwards, some of those students apparently tried to create their own diagrams similar to the diagrams found on the Internet. Unfortunately, such an approach, when extensively used, was doomed to failure. Diagrams that appear in the search engine results are often incomprehensible without a proper commentary, created using different DFD notation standards. In addition, many of them contain errors, some are not DFDs at all. As a result, students who used that approach often created completely wrong solutions. In the assessment of the lecturer, about one third of the students were poorly prepared for the classes, and those people created diagrams without any reflection and they simply copied what they found on the Internet. Their projects were incorrect both from the point of view of the formal use of the notation and the correctness of the model in terms of the proper mapping of the system described in the case study. 
Because the projects made during the classes were evaluated but not graded, the students could consult each other on the condition that they would not obstruct the work of other people. The observer noted frequent direct cooperation of students sitting next to each other, which resulted in the appearance of similar solutions and mistakes among neighboring students. However, similarities between diagrams were not observed in case of projects of students sitting in different parts of the room. Therefore, it was assumed that the participants did not exchange solutions electronically to a greater extent using for example some social networking service. The observer also did not notice any cases of student cooperation by exchanging diagrams through file exchange services, e-mail, or memory sticks.

According to the teacher's assessment, only about $70 \%$ of the projects carried out by students had a satisfactory level. Half of the weak projects (14.6\% of all assignments) contained diagrams which looked to be accidentally made, perhaps by coping incorrect diagrams found on the Internet. Students, when asked about the source of some strange elements of their diagrams, answered directly and without embarrassment that they had found something like this on the Internet. It was difficult to assess what had a greater influence on the poor performance of individual students: Was it a poor preparation for classes or a practice to use Internet sources without reflection? It seems that both factors played a significant role. Poorly prepared students were looking for short-cuts on the Internet, duplicating the work pattern from lower levels of education, where the majority of solutions to exercises in science subjects, or many discussions of typical issues in the humanities can be easily found on the Internet.

\section{Survey Results}

All student that participated in the observed classes were asked to complete an anonymous survey instrument. It was aimed at identifying the most frequently used sources of information, both traditional and electronic. The first question of the survey was designed to identify the most frequently used encyclopedic sources of information (See Figure 2). The respondents had a choice of three forms of encyclopedia:

- traditional printed encyclopedias,

- traditional encyclopedias distributed on CD/DVD-ROM and on the Internet,

- Internet encyclopedias created by users (e.g. Wikipedia).

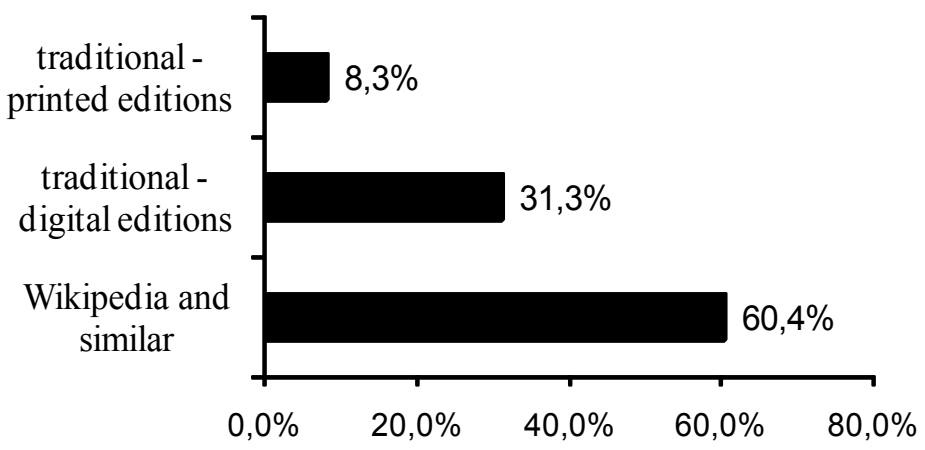

Figure 2. The Most Frequently Used Source of Encyclopedic Information 
The majority of students (60.4\%) marked the encyclopedias created by Internet users as the most frequently used source of encyclopedic information. Whereas, $31.3 \%$ of respondents most often used the electronic edition of a normal encyclopedia. Only 4 people (8.3\% of answers) usually reached for printed versions.

The domination of Wikipedia was confirmed by the indication of sources which the surveyed students did not use at all (See Figure 3). All respondents occasionally used encyclopedias created by Internet users. On the other hand, $20.8 \%$ of respondents never used digital versions of traditional publications. And exactly one third of surveyed students never used printed editions.

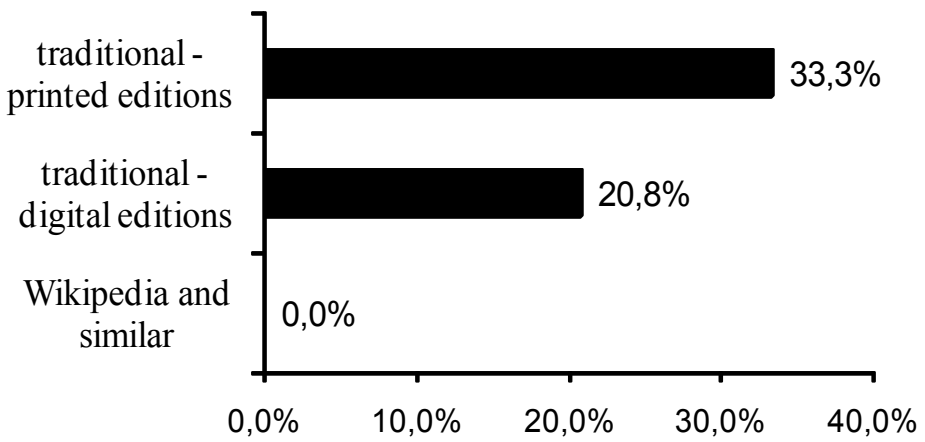

Figure 3. Respondents Never Using Specific Sources of Encyclopedic Information

The purpose of the second part of the survey instrument was to determine what were students' main sources of information about current events. Respondents could point from one to three most frequently used sources out of seven choices. The types of information sources and the number of indications is presented in Table 1.

Table 1. The Most Popular Sources of Information on Current Events, According to the Survey

\begin{tabular}{|l|c|c|}
\hline A source of information & $\begin{array}{c}\text { A number of } \\
\text { indications }\end{array}$ & $\begin{array}{c}\text { Percentage of } \\
\text { respondents }\end{array}$ \\
\hline Articles in Internet portals & 38 & $79.2 \%$ \\
\hline Web editions of newspapers and magazines & 30 & $62.5 \%$ \\
\hline $\begin{array}{l}\text { Online sources containing mainly user-generated } \\
\text { content (e.g. forums, blogs, Facebook, Twitter, } \\
\text { YouTube) }\end{array}$ & 29 & $60.4 \%$ \\
\hline $\begin{array}{l}\text { Directly from other people (colleagues, friends, } \\
\text { family) }\end{array}$ & 26 & $54.2 \%$ \\
\hline Television or radio & 16 & $33.3 \%$ \\
\hline Printed newspapers and magazines & 1 & $2.1 \%$ \\
\hline Others & 0 & $0.0 \%$ \\
\hline
\end{tabular}

The results showed that respondents preferred to use digital sources to obtain information about current events. However, the students preferred Internet portals and web editions of traditional newspapers to online user-generated content. More than half of the respondents also marked the direct contact with other people. In contrast, the number of indications for traditional media was 
very low. In particular, only one participant pointed to the printed press. In this case, the economic factor did not play a significant role. Students have access to free printed sources at the university: daily newspapers and magazines addressed to the student community, and even professional press addressed to business, not to mention the press reading room in the university library.

The last part of the survey instrument was measuring the preferred forms of book reading. The respondents had a choice of four types of books:

- traditional printed books,

- electronic books,

- books printed from an electronic version and

- audiobooks.

This study showed a slightly higher popularity of the printed book over electronic versions (See Figure 4$)$. Of the participants, 34 students (70.8\% of the group) claimed that they often or very often read printed books. Whereas, only 27 respondents $(56.3 \%)$ often or very often read electronic books (that category included both e-books for special readers and other formats, e.g. books scanned to PDF format).
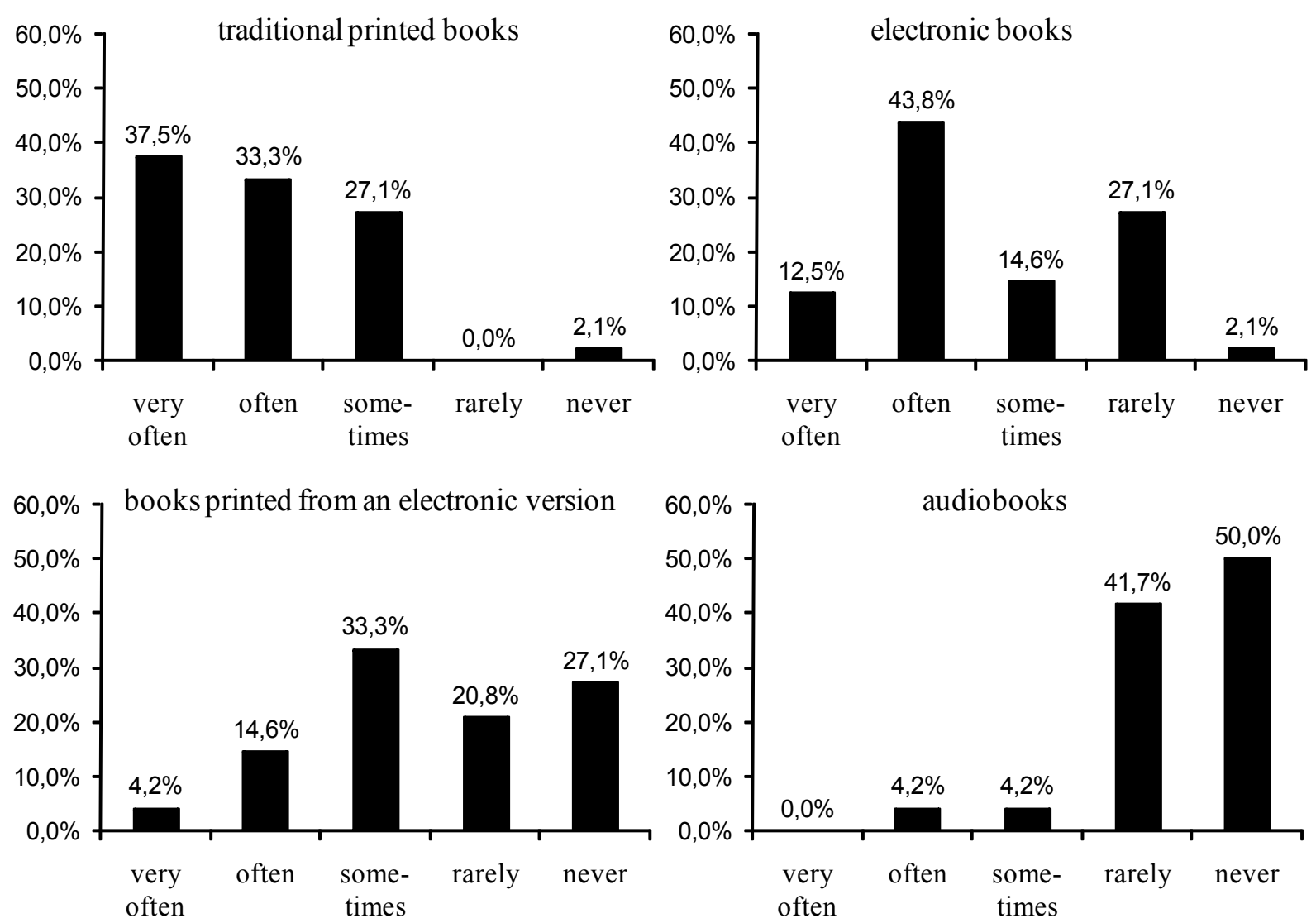

Figure 4. The Frequency of Using Individual Forms of Book Reading, Survey Results 
In addition, nine respondents (18.8\%) often read books printed from an electronic version. The significant popularity of that form of reading can result from printing illegal copies downloaded from the Internet. The popularity of audiobooks was much lower: only two indications (4.2\%). The survey showed that students preferred to read shorter texts (e.g. articles or news) in the digital forms. Only books were favored in the traditional paper form.

\section{Discussion}

Both research methods: the observation and the survey confirmed that students preferred to use electronic devices and digital information resources. This study showed that in preparation for the regular classes, students avoided using more extensive texts explaining the details of procedures and supplementing lecture content. They preferred short forms: slides, diagrams, etc. available digitally, often displaying them on a smartphone screen. That was confirmed by the results of the survey, which showed that in the case of smaller content, such as encyclopedic information and news about current events, students preferred electronic forms.

Students could not or did not want to take notes in class. Instead, they expected that if needed, they would find answers, tips and examples on the Web. Ease of access to information replaces students' own intellectual effort. During case solving in class, students, if possible, preferred direct communication with colleagues. Moreover, the study did not show the use of network communication services and social media during the classes. However, the observation did not include communication between students in the period between classes, when the use of this form of communication was more likely. Hence, it was impossible to assess the phenomenon of communicating via the Internet and social media comprehensively on the basis of the presented research.

The observation did not confirm the phenomenon of multitasking. During classes, the use of computers and smartphones for purposes not related to the course was observed only occasionally and only for very short moments. However, the constant presence of the observer and the teacher walking around the class, helping students with their tasks could have influenced the behavior of students.

This study showed that many students had a problem with assessing the quality of information available on the Internet. Students preferred to use undemanding solutions. They reached for unverified sources, avoided longer studies, and most willingly devoted time to studying examples of diagrams. They were not able to verify the quality of information, its reliability and accuracy. What is more, the problem of information quality occurred in higher education and in a very specialized area.

\section{Conclusions and Recommendations}

The results of this study show that students prefer digital forms of information. The only identified exception is reading books. However, electronic books are almost as popular as traditional books. So, it can be expected that in the near future e-books will dominate reading habits. 
The students should be aware that the sources of information and teaching materials available on the Internet can contain serious errors and misinterpretations. The terms: alternative facts and post-truth have gained recently a lot of public attention (Blake, 2017; Higgins, 2016). The influence of a post-truth era in politics on education has been noticed and discussed (Peters, 2017). Therefore, the use of terms alternative knowledge or post-truth knowledge should be considered in order to stress the problem of quality of information sources used in learning, and in this way, making students aware that not only false facts, but also examples, opinions, solutions and conclusions published on the Internet and on social media may be inconsistent with academic knowledge and good practices defined by professionals.

The observation was limited to one specific course in one academic institution in one country. Conducting similar research in other environments could verify the global nature of the observed behaviors. Most of all, further research should examine the occurrence of this problem among older students. Such a study should verify whether students are becoming aware of the problem of information quality on the Internet during university-level studies.

\section{References}

Anshari, M., Almunawar, M. N., Shahrill, M., Wicaksono, D. K., \& Huda, M. (2017). Smartphones usage in the classrooms: Learning aid or interference? Education and Information Technologies, 22(6), 3063-3079.

Birchall, C. (2011). Knowledge goes pop: From conspiracy theory to gossip. Oxford: Berg.

Blake, A. (2017). Kellyanne Conway says Donald Trump's team has 'alternative facts.' Which pretty much says it all. Washington Post, January 22.

Calderwood, C., Ackerman, P. L., \& Conklin, E. M. (2014). What else do college students "do" while studying? An investigation of multitasking. Computers \& Education, 75, 19-29.

Clark, R. C., \& Mayer, R. E. (2016). E-learning and the science of instruction: Proven guidelines for consumers and designers of multimedia learning. Hoboken, NJ: John Wiley \& Sons.

Dahlstrom, E., \& Jacqueline, B. (2014). ECAR study of undergraduate students and information technology. Research report. Louisville, CO: EDUCAUSE.

Downes, S. (2005). E-learning 2.0. eLearn magazine, 2005(10), 1. Retrieved from https://elearnmag.acm.org/featured.cfm?aid=1104968

Epston, D. (1999). Co-research: The making of an alternative knowledge. In Narrative therapy and community work: A conference collection, 1, 137-156. Adelaide, SA: Dulwich Centre Publications.

Gaebel, M., Kupriyanova, V., Morais, R., \& Colucci, E. (2014). E-Learning in European higher education institutions: Results of a mapping survey conducted in October-December 2013. European University Association.

Garrison, J. C. (2015). Getting a “quick fix": First-year college students' use of Wikipedia. 
Guy, R. (2012). The use of social media for academic practice: A review of literature. Kentucky Journal of Higher Education Policy and Practice, 1(2), Article 7.

Higgins, K. (2016). Post-truth: a guide for the perplexed. Nature News, 540(7631), 9.

Kim, K. S., Sin, S. C. J., \& Tsai, T. I. (2014). Individual differences in social media use for information seeking. The Journal of Academic Librarianship, 40(2), 171-178.

Ko, E. H., Chiu, D. K., Lo, P., \& Ho, K. K. (2015). Comparative study on m-learning usage among LIS students from Hong Kong, Japan and Taiwan. The Journal of Academic Librarianship, 41(5), 567-577.

Kon, H., Kobayashi, H., Sakurai, N., Watanabe, K., Yamaga, Y., \& Ono, T. (2017). Personal computer versus personal computer/mobile device combination users' preclinical laboratory e-learning activity. Journal of Investigative and Clinical Dentistry, 8(4). Retrieved May 28, 2018 from https://www.ncbi.nlm.nih.gov/pubmed/27863113

Laurillard, D. (2013). Rethinking university teaching: A conversational framework for the effective use of learning technologies. London, UK: Routledge.

Lepp, A., Barkley, J. E., \& Karpinski, A. C. (2015). The relationship between cell phone use and academic performance in a sample of US college students. Sage Open, 5(1), Retrieved from http://journals.sagepub.com/doi/full/10.1177/2158244015573169

McGarr, O. (2009). A review of podcasting in higher education: Its influence on the traditional lecture. Australasian Journal of Educational Technology, 25(3), 309-321.

O’Callaghan, F. V., Neumann, D. L., Jones, L., \& Creed, P. A. (2017). The use of lecture recordings in higher education: A review of institutional, student, and lecturer issues. Education and Information Technologies, 22(1), 399-415.

Patterson, M. C. (2017). A naturalistic investigation of media multitasking while studying and the effects on exam performance. Teaching of Psychology, 44(1), 51-57.

Peters, M. A. (2017). Education in a post-truth world. Educational Philosophy and Theory, $49(6), 563-566$

Polak, P. (2011). Internet and traditional information sources - a survey of usage by Polish and Turkish students. Proceedings of the IADIS International Conference e-Society 2011, 125-132.

Polak, P. (2013). Incorporating new media in human to human communication - the case of occasional greetings. Proceedings of the International Conference e-Society 2013, 131138.

Polak, P. (2015). Introduction to business information systems. Warszawa, Poland: Szkoła Główna Handlowa w Warszawie

Polak, P. (2016). The practices of accessing and saving information. A survey of using digital vs traditional media. IADIS International Journal on WWW/Internet, 14(1), 39-56. 
Rosen, L. D., Carrier, L. M., \& Cheever, N. A. (2013). Facebook and texting made me do it: Media-induced task-switching while studying. Computers in Human Behavior, 29(3), 948-958.

Selwyn, N. (2007). The use of computer technology in university teaching and learning: a critical perspective. Journal of computer assisted learning, 23(2), 83-94.

SGH (2016). Curricula and study plans for first and second cycle programmes in English at $S G H$, Warsaw, Poland: Szkoła Główna Handlowa w Warszawie.

Shen, X. L., Cheung, C. M., \& Lee, M. K. (2013). What leads students to adopt information from Wikipedia? An empirical investigation into the role of trust and information usefulness. British Journal of Educational Technology, 44(3), 502-517.

Tassone, A., Liu, J. J., Reed, M. J., \& Vickers, K. (2017). Multitasking in the classroom: Testing an educational intervention as a method of reducing multitasking. Active Learning in Higher Education, Retrieved from http://journals.sagepub.com/doi/abs/10.1177/ 1469787417740772

Terry, C. A., Mishra, P., \& Roseth, C. J. (2016). Preference for multitasking, technological dependency, student metacognition, \& pervasive technology use: An experimental intervention. Computers in Human Behavior, 65, 241-251.

Tindell, D. R., \& Bohlander, R. W. (2012). The use and abuse of cell phones and text messaging in the classroom: A survey of college students. College Teaching, 60(1), 1-9.

Venkatesh, V., Rabah, J., Fusaro, M., Couture, A., Varela, W., \& Alexander, K. (2016). Factors impacting university instructors' and students' perceptions of course effectiveness and technology integration in the age of web 2.0. McGill Journal of Education, 51(1), 533562.

Yourdon, E. (2006). Just enough structured analysis. Retrieved September 23, 2007 from: http://www.yourdon.com/jesa/pdf/JESA mpmb.pdf

Zhuang, Y., Ma, H., Xie, H., Leung, A. C. M., Hancke, G. P., \& Wang, F. L. (2016). When innovation meets evolution: An extensive study of emerging e-learning technologies for higher education in Hong Kong. Proceedings of the International Symposium on Emerging Technologies for Education, 574-584.

\section{Author's Biography}

Przemyslaw Polak is a senior lecturer and a director of the Postgraduate Studies in Business Analysis in the Institute of Information Systems and Digital Economy at the Warsaw School of Economics. He is also an independent consultant in the field of information systems. 